\title{
O Professor de Computação em Formação: Experiências de Conexões de Saberes nos Anos Iniciais do Ensino Fundamental
}

\author{
Pietro Bompet $^{1}$, Pauleany Morais ${ }^{2}$ \\ ${ }^{1}$ Professor de Computação (em Formação) - Universidade Federal da Bahia (UFBA) \\ Salvador - Bahia - Brasil \\ 2Professora da Licenciatura em Informática - Campus Zona Leste - Instituto Federal de \\ Ciência, Educação e Tecnologia do Rio Grande do Norte (IFRN) \\ Natal - Rio Grande do Norte - Brasil \\ Campus Salvador (Cooperação Técnica) - Instituto Federal de Ciência, Educação e \\ Tecnologia da Bahia (IFBA) \\ pietro.bompeteufba.br, pauleany.moraiseifrn.edu.br
}

\begin{abstract}
This article sought to analyze the contributions of activities with connections of knowledge involving Computer Science and Visual Arts in the early years of Elementary Education in the context of a public school in Salvador/BA. As a theoretical-methodological approach, a literature review on computer teaching and the analysis of a systematized experience in school through experience in Supervised Internships using the set of techniques of Computer Science Unplugged and Computational Thinking were used. The results show the relevance of computer teaching at school in the absence of curricular and professional references that guide educational practice, as well as professionals that guide these internships. lines and must be in the first page of the paper.
\end{abstract}

Resumo. O presente artigo buscou analisar as contribuições de atividades com conexões de saberes envolvendo a Computação e Artes Visuais nos anos iniciais do Ensino Fundamental no contexto de uma escola pública de Salvador/BA. Como encaminhamento teórico-metodológico utilizou-se da revisão de literatura acerca do ensino da Computação e a análise de uma vivência sistematizada na escola por meio de experiências nos Estágios Supervisionados utilizando o conjunto de técnicas da Computação Desplugada e o Pensamento Computacional. Os resultados apresentam a relevância do ensino da Computação na escola diante da ausência de referenciais curriculares e profissionais que orientem a prática educacional, bem como profissionais que orientem os referidos estágios.

\section{Introdução}

A partir da presença das tecnologias digitais nos ambientes escolares, o papel estratégico no ensino e compartilhamento dos saberes da Computação em sociedade, surge em 1997 o curso

\footnotetext{
${ }^{1}$ Pesquisador no Grupo de Estudos e Pesquisas em Avaliação para Aprendizagem, Grupo de Pesquisa Educação, Comunicação e Tecnologias (GEC) e no Onda Digital - Grupo de Pesquisa e Extensão em Informática, Educação e Sociedade, todos vinculados à UFBA. Bolsista de Iniciação Científica do Conselho Nacional de Desenvolvimento Científico e Tecnológico (CNPq).

${ }^{2}$ Pesquisadora Colaboradora no Onda Digital - Grupo de Pesquisa e Extensão em Informática, Educação e Sociedade (UFBA).
} 
de formação de professores específico da área de Ciência de Computação, em nível de graduação: a Licenciatura em Computação (LC). Em sua monografia, o licenciado em Computação Lafayette Pinheiro (2017) apresenta que a LC é um curso possui o caráter multidisciplinar, de modo a englobar saberes científicos, didáticos e tecnologias na matriz curricular.

A presença da Computação na Educação Básica é uma temática amplamente debatida pela comunidade científica nas últimas décadas. A pauta é recorrente nos eventos acadêmicos da área, especialmente aqueles que possuem articulação com a Educação (a exemplo, o Workshop da Licenciatura em Computação - WLIC $^{3}$ e as trilhas específicas do Simpósio Brasileiro de Informática na Educação - $\mathrm{SBIE}^{4}$ envolvendo Computação \& Educação). Mesmo diante da crescente produção acadêmica nesse contexto, a divulgação científica para além dos "muros da academia" ainda é vagarosa e gradual, restringindo o acesso ao conhecimento aos seus pares da mesma área, quando não do mesmo grupo pertencente. Esse fato influencia o desconhecimento do grande público sobre as contribuições da grande área da Ciência da Computação para a sociedade, especialmente do curso de Licenciatura em Computação e seus licenciandos, culminando na escassez de oportunidades para atuação na Educação Básica.

De acordo com Almeida e Valente (2019, p. 213) "diversos países têm procurado alterar seu currículo no sentido de focar os aspectos da programação ou de conceitos da Ciência da Computação, inclusive nos primeiros anos da Educação Básica". Relatos de atividades envolvendo a referida área e os alunos do Ensino Fundamental, a exemplo do estudo de Pereira, Araújo e Bittencourt (2019), apresentam significativas contribuições na formação cidadã das crianças e pré-adolescentes, compreendo a importância da Computação e suas tecnologias para a vida contemporânea e formação dos escolares.

De acordo aos Referenciais de Formação em Computação: Educação Básica [Raabe et al. 2017, p. 2], a Computação pode ser entendida como "uma ciência que investiga a resolução de problemas". Nesse sentido, o pensamento computacional e os raciocínios da Abstração, Composição e Decomposição, Algorítmico, Reconhecimento de Padrões são compreendidos pelos autores deste artigo como pilar fundamental para os processos de resolução de problemas.

No contexto local, o currículo vigente para os anos iniciais da Educação Básica no município de Salvador/BA não apresenta obrigatoriedade para ensino de conteúdos e/ou componentes curriculares da área de Computação. A mesma área apenas é encontrada em escolas da rede estadual de Educação do estado da Bahia, sendo vinculados aos cursos de formação técnica e profissional de alunos por meio de estudos integrados e/ou subsequentes ao Ensino Médio.

Diante desse cenário, esta pesquisa se origina das vivências de um professor de Computação em formação ${ }^{5}$, durante os últimos dois estágios supervisionados realizados em uma escola da rede pública de ensino de Salvador/BA. O objetivo da investigação consistiu

\footnotetext{
3 Última edição realizada em 2019 - V Workshop da Licenciatura em Computação. Disponível em: http://www.wlic.upe.br/. Acesso em: 17 jun. 2020.

${ }^{4}$ Trilhas relacionadas à Educação na edição atual do SBIE, sendo disponibilizadas em: https://cbie.ceiebr.org/2020/eventos/sbie.html. Acesso em: 17 jun. 2020.

${ }^{5}$ Denominação utilizada para o aluno de graduação do curso de Computação - Licenciatura, sendo apresentado também como "licenciando em Computação" ou "licenciando-estagiário" (em referência a participação nos estágios supervisionados).
} 
em analisar as contribuições do ensino da Computação a partir da integração aos componentes curriculares já existentes no currículo escolar nos anos iniciais do Ensino Fundamental. Como destaque, este relato apresenta a interação da área da Computação com Artes Visuais a partir da supervisão in loco de uma professora que leciona Artes Visuais juntamente com um professor-orientador da Computação vinculado a instituição federal de Educação. $\mathrm{O}$ material analisado foi proveniente das produções de alunos do $2^{\circ}$ ao $3^{\circ}$ do Ensino Fundamental I e realizadas no ano de 2018.

A escola municipal escolhida para realização dos estágios supervisionados não apresentava infraestrutura tecnológica para abrigar um laboratório de Informática, tampouco possuía recursos computacionais disponíveis para os alunos. Entretanto, compreendendo a importância da Computação para a formação cidadã, além do seu potencial arqueável para o trabalho, ensino e aprendizagem em qualquer contexto, inclusive com a utilização de quaisquer instrumentos/procedimentos didáticos (não necessariamente digitais), optou-se para escolha da instituição como campo de atuação.

A partir do exposto, o artigo está dividido da seguinte forma: na segunda seção discute-se estudos sobre o ensino da Computação na escola pública e os Referenciais Curriculares norteadores para a Educação Básica; na terceira seção buscou-se a análise de atividades planejadas com conexões de saberes entre Computação e Artes Visuais; por último, reflexões pontuais sobre a vivência formativa do ensino da Computação na Educação Básica.

\section{O Ensino de Computação e a vivência escolar do Professor em Formação}

Diante do atual contexto de cultura digital, em especial, as implicações no campo da Educação e a formação de cidadãos na sociedade da informação, os cursos de LC adquiriram importância substancial ao formarem novos profissionais para atuarem na docência. Em contrapartida, os estudos atuais destacam que os cursos de licenciatura em Computação são desconhecidos pela sociedade e invisibilizados durante o ingresso na graduação [Pinheiro 2017]; ausência da participação do professor de Computação em formação nas proposições políticas curriculares [Paiva et al. 2017]; os baixos salários, o desprestígio da profissão docente e as condições mínimas para os processos formativos no desenvolvimento do trabalho docente na escola [Souza, Morais e Júnior 2015]; carência de profissionais docentes licenciados em Computação na escola [Morais e Júnior 2015].

Segundo os professores Bompet e Alves (2019), a escola se configura como espaço para o fomento das experiências e dos aprendizados, da mesma maneira que se apresenta repleta de tensões e desafios para os sujeitos envolvidos. Aos licenciandos presentes no espaço escolar faz-se necessário permanentes ressignificações no processo de constituição do ser docente e, consequentemente, na construção/afirmação das suas identidades profissionais.

A escola, sendo um dos principais campos desses profissionais é marcada por tensões e dilemas, tais como a afirmação da profissão escolhida, transformações das posturas no exercício da docência e ressignificações da constituição da identidade que podem até provocar a crise da identidade docente [Bompet e Alves 2019, p. 10-11].

Ao refletir acerca das práticas e conteúdos escolares, tendo como referências as mudanças ocorridas nesse espaço devido a evolução das tecnologias digitais contemporâneas, nota-se que "a estruturação dos conteúdos abordados e as práticas 
pedagógicas necessitam se adequar aos perfis e necessidades formativas dos alunos" [Bompet e Alves 2019, p. 3]. Nesse sentido, a Licenciatura em Computação vem desenvolvendo um papel primordial no fomento de práticas com utilização de tecnologias e seus diversos recursos, bem como o desenvolvimento de atividades interdisciplinares. A esse respeito, os autores Falcade et al. (2019, p. 11) alertam que os licenciandos em Computação necessitam produzir "alternativas de trabalho que vão além da pesquisa na Internet".

O papel do professor de Computação em formação consiste em viabilizar estratégias e práticas de inclusão de conhecimentos fundamentais da Ciência da Computação com significativas possibilidades de integrar conhecimentos em diversas áreas do conhecimento. Segundo os mesmos autores, a integração curricular "trata-se de um movimento que busca, além da prática, realizar a integração curricular e exercitar a pesquisa docente desde a formação inicial" [Falcade et al. 2019, p. 12].

$\mathrm{Na}$ busca por práticas que contemplem os conteúdos, instrumentos/procedimentos didáticos específicos da Computação, esses necessários para a formação dos cidadãos na contemporaneidade, as atividades envolvendo o pensamento computacional $^{6}$ são apresentadas como promissoras na abordagem inicial de temáticas da área, seja na Educação Básica ou em cursos de formação inicial e continuada. A aprendizagem desenvolvida por meio das habilidades necessárias a Computação, particularmente pela programação pode estimular a criança o potencial "de articular o trabalho de sua própria mente e, particularmente, a interação entre ela e a realidade no decurso da aprendizagem e do pensamento" [Papert 1971, p. 3].

Os estudos de Jeanette Wing (2006) iniciaram as discussões de maneira pioneira do termo pensamento computacional pela primeira vez na Ciência da Computação. $\mathrm{O}$ significado do pensamento computacional refere-se à resolução de problemas, simulação, decomposição, automação, abstração, modelação, pensamento recursivo, paralelo e sequencial [WING 2006]. Outros estudo norte-americano, desenvolvido pela Computer Science Teachers Association (CSTA) apresenta uma definição para a área de Ciência da Computação como "o estudo dos computadores e processos algorítmicos, incluindo seus princípios, designs de hardware e software, suas aplicações e impactos na sociedade"7 [CSTA 2011, p. 1].

No contexto brasileiro, Araújo, Andrade e Guerreiro (2016) realizaram um mapeamento dos estudos que envolvessem o pensamento computacional nas práticas de ensino. Os mesmos autores constataram que existem diversos relatos acerca de práticas/atividades inspirada a partir das técnicas da Computação Desplugada [Bell et al. 2011] que favorece o ensino da Computação sem necessidade de utilização de recursos digitais. Nesse sentido, as atividades foram desenvolvidas numa perspectiva de conexão de saberes e apresenta como referência a utilização de materiais concretos já existentes na escola com destaque para desenvolvimento de conceitos e práticas da Computação e Artes Visuais.

A partir do exposto, buscou-se desenvolver atividades que rompessem com qualquer possibilidade de "fragmentação das ciências e dos conhecimentos produzidos por elas e onde

\footnotetext{
${ }^{6}$ Os autores deste artigo corroboram com Ferreira et al. (2015) ao apresentarem o conceito de pensamento computacional em contraposição ao raciocínio computacional, de modo que o primeiro é utilizado em contextos específicos e o segundo "[...] está relacionado ao pensamento analítico e ao raciocínio dedutivo - que envolve a lógica e a matemática" (p. 257).

${ }^{7}$ Do original "the study of computers and algorithmic processes, including their principles, their hardware and software designs, their applications, and their impact on society".
} 
simultaneamente se exprime a resistência sobre um saber parcelado" [Thiesen 2008, p. 547]. Portanto, a perspectiva de conexão de saberes embasa este estudo, permitindo aos sujeitos envolvidos a busca necessária à produção e à socialização do conhecimento.

\section{Proposição de conexão de saberes no ensino da Computação e Artes Visuais}

Para realização dos estágios supervisionados, foi proposto a criação de uma sequência didática com base nas conexões de saberes que contemplam conteúdos da Computação e de outra área do conhecimento, sendo essa já presente ao currículo da Educação Básica e no contexto escolar escolhido. A partir disso, optou-se pela escolha do componente curricular de Artes Visuais, sendo a vivência docente relatada nesta investigação realizada durante os estágios supervisionados finais do curso de Licenciatura em Computação.

Para fim de sistematização do material produzido e aquele a ser apresentado neste artigo, os autores deste estudo destacaram 2 (duas) atividades realizadas em turmas do $2^{\circ} \mathrm{e}$ $3^{\circ}$ ano do Ensino Fundamental, com alunos/as entre 6 (seis) e 9 (nove) anos. O material utilizado para a produção das atividades se deu exclusivamente com recursos já encontrados no contexto escolar e de baixo valor econômico, como lápis coloridos e gizes de cera.

Os conteúdos provenientes das áreas do conhecimento abordadas nas atividades, são detalhadas a seguir: Para Computação, os raciocínios computacionais da abstração, decomposição e reconhecimento de padrões foram trabalhados; e, em relação a área de Artes Visuais, a composição das cores primárias, secundárias e terciárias, bem como a utilização de técnicas de pintura com traços finos foram incorporadas as tarefas.

A atividade 01 recebeu o título de Círculo Cromático e abrangeu o conteúdo das cores e o raciocínio computacional da Abstração. Os alunos precisam compor a imagem com as cores relacionadas ao subgrupo pertencente (Primárias, Secundárias e Terciárias) de modo a identificarem a composição/interação de cada cor com as adjacentes. A figura 1 apresenta o desenho inicial da atividade (imagem a esquerda) e as orientações apresentadas para a turma com a localização das cores na atividade (imagem a direita).
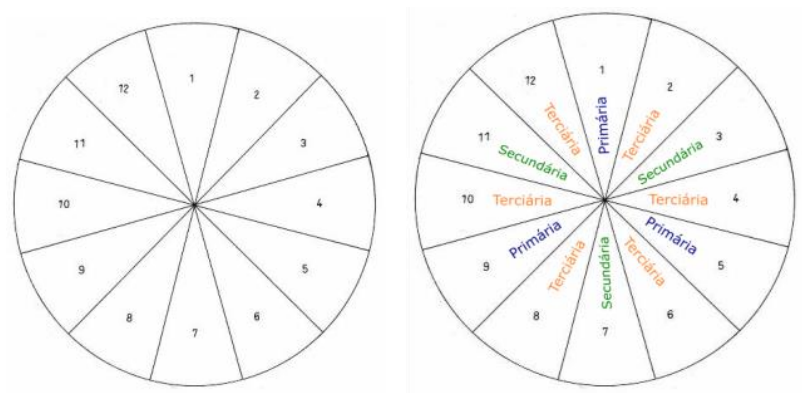

Figura 1. Atividade do Círculo Cromático em etapa inicial Fonte: Arquivo pessoal dos autores (2018)

A abstração inicialmente foi posta em desenvolvimento a partir da divisão da respectiva atividade em etapas, sendo a primeira específica para identificação das cores pertencentes a cada subgrupo; a segunda voltada para separação dos lápis de cor para composição das seções e associação das cores aos números dispostos na atividade (1 a 12). A figura 2 apresenta a composição das cores primárias e secundárias nas atividades dos alunos. 

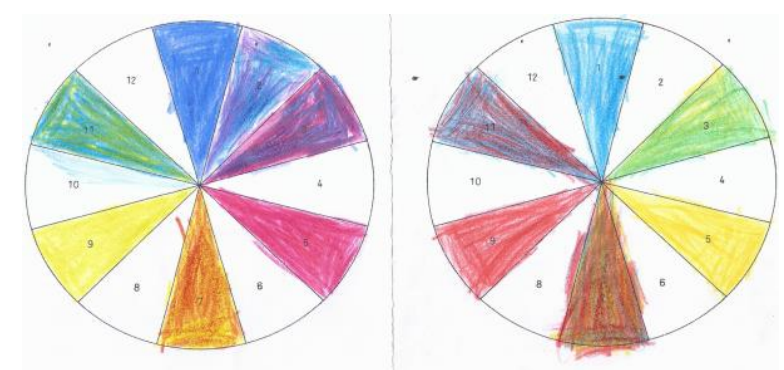

Figura 2. Preenchimento das cores primárias e secundárias

Fonte: Arquivo pessoal dos autores (2018)

Ao final da atividade 1, destaca-se que os alunos conseguiram diferenciar as cores dispostas no material didático antes de marcar os espaços delimitados na tarefa impressa, agrupando-as de acordo a cada subgrupo, para então realizar o registro (pintura). Nesse contexto, a Abstração esteve presente no momento da escolha de elementos primordiais para composição da atividade, bem como a definição de objetivos, organizados em etapas, para a concretude do objetivo.

A atividade 2, denominada História Desenhada, teve como objetivo a criação de representações com base nos elementos principais de uma história contada. Para a produção de cada atividade, cada aluno deveria escolher um conjunto de elementos e representa-los em suas próprias produções. Em acordo com a turma, e após a primeira leitura conjunta, os alunos escolheram representar obrigatoriamente em seus desenhos 3 (três) elementos, a saber: uma árvore com a presença de um fruto na cor lilás; uma casa; e um personagem com traços humanos.

No decorrer da etapa de produção dos desenhos em sala, o raciocínio computacional de Abstração se fez presente a partir da interpretação os alunos acerca dos elementos obrigatórios e optativos de cada produção, assim como sua respectiva representação. A divisão em etapas, com destaque para a representação daqueles acordados como obrigatórios, para posterior preenchimento daqueles não essenciais é interpretado pelos autores deste artigo como desenvolvimento do raciocínio da Composição e Decomposição.

A figura 3 tem como referência uma produção que não atendeu totalmente o objetivo proposto na referida atividade, devido à ausência do elemento obrigatório "árvore". Reiterase que a atividade não foi invalidada ou desconsiderada, mas discutida com a turma acerca do atendimento aos critérios negociados e quais etapas de produção do desenho necessitariam ser realizadas/revisadas.

Figura 3. Atividades com ausência do elemento "árvore". Fonte: Arquivo pessoal dos autores (2018) 
Já na figura 4 é apresentado dois exemplos de produções que atenderam o objetivo proposto, com destaque para incorporação de outros elementos não presentes na história contada (elementos optativos). A partir do estímulo do desenvolvimento da habilidade de Abstração, nota-se a diversidade nas representações promovidas pelos alunos em suas produções, apresentando os elementos negociados nas atividades com distintas características.

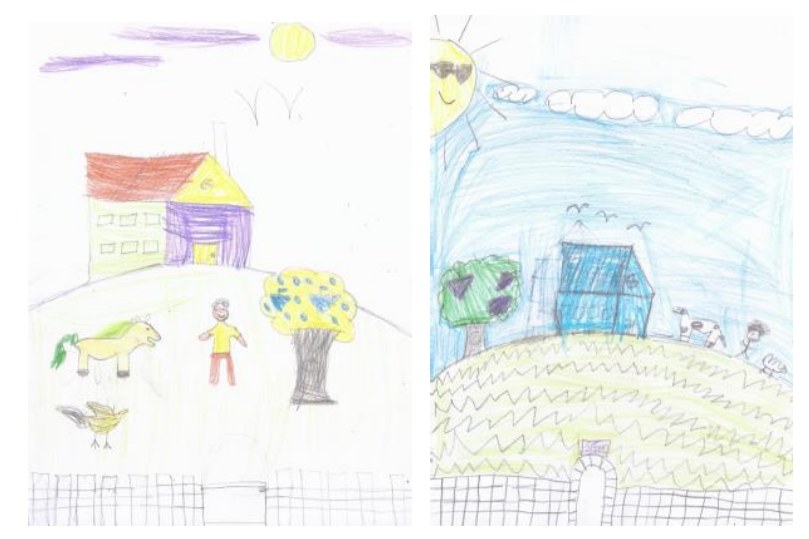

Figura 4. Produções que atenderam integralmente o objetivo da atividade 2 Fonte: Arquivo pessoal dos autores (2018)

No que concerne aos pilares do Pensamento Computacional trabalhados nas atividades, dentre eles a abstração, o reconhecimento de padrões e a composição e decomposição, notou-se que os alunos conseguiram alcançar os objetivos didáticos por meio da utilização das habilidades computacionais integradas as etapas das tarefas. Como exemplo, a saber: na primeira atividade (Círculo Cromático), a definição das cores que iriam compor inicialmente a atividade foi desenvolvida pelo raciocínio da Abstração, além da Composição e Decomposição no momento da separação das cores em subgrupos (Primárias, Secundárias e Terciárias); e na segunda atividade (História Contada), ao estabelecerem os elementos/personagens principais que deveriam estar presentes nas produções individuais, os alunos mais uma vez trabalharam o raciocínio da Abstração, juntamente com a Composição e Decomposição dos elementos.

\section{Considerações Finais}

As atividades realizadas buscaram promover a conexão de saberes entre a Computação e Artes Visuais em situações de vivência concreta na escola pública. As experiências significativas, interpretadas pelos autores deste trabalho como a compreensão das dinâmicas do espaço escolar vivenciado, culminaram em reflexões acerca da relação entre os sujeitos escolares e o conhecimento, bem como o ofício de ser professor e as influências para a constituição, afirmação ou repulsa da identidade docente desse profissional em formação.

Apesar da existência de uma referência nacional para o ensino da Computação na concretude real das ações na escola pública não foram incorporados ao currículo. O contexto da Educação na Bahia segue os mesmos parâmetros, exigindo do professor em formação elaborações próprias e solitárias para o planejamento, realização e análise das suas produções. No âmbito especial dos estágios na licenciatura, os licenciandos-estagiários encontram-se sem prospecção de práticas profissionais amparadas pelos seus pares licenciados com experiência na docência em Computação. Neste caso em específico, reiterase que o licenciando-estagiário, durante todo o percurso formativo dos estágios, não foi 
contemplado com o amparo de orientações didático-metodológicos, tampouco com as referências profissionais de licenciados em sua própria área de formação e práticas existentes na escola.

A conquista pelo espaço na escola, bem a confiança dos sujeitos envolvidos (a professora-supervisora, os educandos presentes nas turmas, coordenação e gestão escolar) também se configurou com fator determinante para o desenvolvimento das ações. As práticas in loco possibilitaram um marco histórico-curricular do ensino da Computação naquela realidade escolar devido a experiência inovadora e, até então desconhecida, da existência da área com o fomento de práticas na Educação Básica.

Ao utilizar o conjunto de práticas provenientes da Computação Desplugada em meio ao contexto já apresentado, proporcionou que as atividades pudessem ser realizadas, respeitando as condições destinadas às ações da/na escola, com a utilização de materiais já existentes e utilizados nas aulas de Artes Visuais, bem como o potencial para sistematização inicial dos conceitos fundamentais da Ciência da Computação.

Por fim, os autores desta investigação ressaltam que a vivência na escola sem as referências curriculares e profissionais, comprometem a conquista de espaços condizentes e necessárias para a formação inicial docente do professor de Computação. Este estudo, portanto, apresentou que a postura do licenciando em Computação necessitou ser repensada, sendo essa marcada pela autonomia desde o planejamento até a conclusão das ações na escola. As atividades desenvolvidas se configuraram como experiências significativas de interações entre os estudos teóricos do ensino da Computação e fomento da práxis, constituindo saberes pedagógicos inerentes a formação inicial em cursos de licenciatura.

\section{Referências}

Almeida, M. E. B., \& Valente, J. A. (2019). Pensamento Computacional nas Políticas e nas Práticas em Alguns Países. Revista Observatório, Palmas, v. 5, n. 1, p. 202-242, jan-mar. 2019.

Araújo, A. L., Andrade, W., \& Guerrero, D. (2016). Um Mapeamento Sistemático sobre a Avaliação do Pensamento Computacional no Brasil. In: Anais dos Workshops do Congresso Brasileiro de Informática na Educação (Vol. 5, No. 1, p. 1147).

Bell, T., Witten, I, H. \& Fellows, M. (2011). Computer Science Unplugged: Ensinando Ciência da Computação sem o uso do computador. Tradução coordenada por Luciano Porto Barreto.

Bompet, P., \& Alves, R. (2019). Ressignificações da Identidade Docente na Formação Inicial de Professores/as: saberes e fazeres na licenciatura. In: XIII Colóquio Internacional Educação e Contemporaneidade, São Cristóvão. Disponível em: https://ri.ufs.br/bitstream/riufs/13180/37/36.pdf. Acesso em: 18 jun. 2020.

Computer Science Teacher Association - CSTA. (2011). CSTA K-12 Computer Science Standards. CSTA Standards Task Force. ACM - Association for Computing Machinery

Falcade, A., Duarte, A. V., Richter, C., dos Santos, J. N., Dornelles, L., \& Barbosa, S. (2019). Prática enquanto componente curricular: um relato de experiência. In: Anais dos Workshops do Congresso Brasileiro de Informática na Educação (Vol. 8, No. 1, p. 11). 
Morais, P., \& Júnior, F. S. (2014). Formação Articulada entre Docentes na Disciplina de Prática de Ensino para a Licenciatura em Informática do IFRN. In: Anais do XXII Workshop sobre Educação em Computação (pp. 70-79). SBC.

Paiva, L. F., Bompet, P., Corlett, E. F., Matos, E., \& Schwarzelmuller, A. (2017). A formação, o trabalho e a identidade profissional do Professor de Computação: um mapeamento sobre a Licenciatura em Computação. In: VI Congresso Brasileiro de Informática na Educação, Recife. org.crossref.xschema._1.Title@41f68938, 2017. v. VI. p. 893-901.

Papert, S. (1971). Teaching Children Thinking, Logo Memo $\mathrm{n}^{\mathrm{o}}$ 2. Disponível em: https://archive.org/details/bitsavers_mitaiaimAI_471587. Acesso em: 15 jun. 2020.

Pereira, F., Araújo, L., \& Bittencourt, R. (2019). Intervenções de Pensamento Computacional na Educação Básica através de Computação Desplugada. In: Anais do Workshop de Informática na Escola, 25(1), 315. doi:http://dx.doi.org/10.5753/cbie.wie.2019.315.

Pinheiro, L. J. M. (2017). Estudo com egressos da Licenciatura em Computação da Universidade de Brasília: as influências do curso na vida profissional e pessoal dos exalunos. 74f. Trabalho de Conclusão de Curso (Graduação) - Universidade de Brasília, Brasília. Disponível

em: http://bdm.unb.br/bitstream/10483/19520/1/2017_LafayetteJunioMendon\%C3\%A7aPin heiro tcc.pdf. Acesso em: 14 jun. 2020.

Raabe, A. A., Zorzo, A., Frango, I., Ribeiro, L., Granville, L. Z., Salgado, L., Cruz, M., Bigolin, N., Cavalheiro, S., \& Fortes, S. (2017). Referenciais de formação em computação: Educação básica. In: Workshop sobre Educação em Computação, Sociedade Brasileira de Computação (SBC), pages 1-9.

Thiesen, J. da S. (2008). A interdisciplinaridade como um movimento articulador no processo ensino-aprendizagem. Rev. Bras. Educ. [online], vol.13, n.39, p. 545-554.

Souza, O. S., Morais, P. S., \& Júnior, F. C. S. (2015). Um Estudo sobre a Evasão no Curso de Licenciatura em Informática do IFRN - Campus Natal - Zona Norte. In: XXIII Workshop sobre Educação em Computação (WEI).

Wing, J. M. (2006). Computational thinking. Communications of the Acm, 49(3):33-35. 